\title{
A mediação da informação e o protagonismo social: ex- perimentando a construção de um modelo em uma co- munidade brasileira
}

\author{
Maria Giovanna Guedes Farias* \\ Aida Varela Varela**
}

Artículo recibido:

9 de mayo de 2015

Artículo aceptado:

11 de enero de 2016

\section{Resumen}

Este artículo expone la presentación de resultados de una investigación en Ciencias de la Información, cuyo objetivo se centró en planear, construir y experimentar un modelo de mediación de la información con el objetivo de ofrecer apoyo teórico-metodológico a fin de impulsar el protagonismo social en la población de una comunidad en el nordeste de Brasil. Para esta comunicación se eligió el extracto centrado en la trayectoria diseñada para la producción del modelo de mediación, a partir de fundamentos teóricos experimentados a lo largo de la investigación. Tal experimentación fue apoyada por la mediación de la información y por el paradigma social de las Ciencias de la

* Universidade Federal do Ceará, Brasil.

** Universidade Federal da Bahia, Brasil.

mgiovannaguedes@gmail.com

varela@ufba.br 
Información. En el núcleo de este modelo, los estudios fueron dirigidos hacia el desarrollo de acciones realizadas para y con los sujetos, es decir, centrándose en la alteridad. El enfoque metodológico utilizado se caracteriza por una investigación participativa de naturaleza cualitativa. Los resultados indican que la dinámica de planificación y ejecución del modelo de mediación de la información permitió la potenciación del protagonismo social en los sujetos de investigación, que se apropiaron de la información, utilizándola para una posible emancipación social, económica y política.

Palabras clave: Mediación de la Información; Protagonismo Social; Comunidad Brasileña; Ciencias de la Información.

\section{Mediation of information and social leadership: ex- periencing the construction of a model in a Brazilian community \\ Maria Giovanna Guedes-Farias and Aida Varela-Varela}

\section{Abstract}

This paper presents the research results of an Information Science research experience focused on planning and building an information mediation model for the purpose of providing theoretical and methodological support to encourage social leadership among a community in the northeastern of Brazil. This paper focuses specifically the production of the mediation model from the theoretical foundations emerging during the research. This trial deploys mediation of information and the social paradigm of Information Science. At the core of this model, studies were aimed at the development of actions focusing on otherness and performed for and with the subject. The methodological approach may be described as a participative research of a qualitative nature. Results indicate that the dynamic planning and execution of the information mediation model enabled the enhancement of social leadership in the subjects studied, who appropriated information, while using it for social, economic and political emancipation.

Keywords: Information Mediation; Social role; Empowerment; Brazilian community; Information Science. 


\section{INTRODUÇÃO}

$\mathrm{M}$ ediar o processo de dinamização do protagonismo social em moradores de uma comunidade requer do mediador autoconhecimento profissional, e o entendimento de que ele é o principal protagonista de todas as ações implantadas no campo de pesquisa. Além disso, o mediador deve ter em mente que estas ações devem ser realizadas sempre em conjunto, e de forma dialógica com todos os sujeitos envolvidos (Klein, 2009).

O protagonismo é um conceito cujo significado é relacional, na medida em que só pode ser compreendido em relação aos diferentes sujeitos, envolvidos num acontecimento. Por isso, é preciso que o mediador liberte-se de ideias conversadoras e estáticas, para poder sentir as demandas de um grupo, se conscientizando de seu papel na sociedade perante a responsabilidade social da área em que atua, procurando incentivar a tolerância e abertura por parte dessa sociedade face à diversidade cultural e étnica dos que vivem à margem.

Assegurando (Caltabiano, 2006) assim, que o protagonismo social e político possa contribuir para a participação dos indivíduos em processos decisórios - um antídoto contra a indiferença e o isolamento social -, uma forma de afrontar problemas que parecem insolúveis, mas que ao final possibilita a descoberta ou a recuperação de uma energia contagiante do agir coletivo, da convicção de poder mudar as coisas, do cultivo da arte da solidariedade, do empenho em supervisionar as ações políticas e governamentais, ou seja, de assumir o controle do próprio destino, desempenhando papel ativo na sociedade.

Neste contexto, compreende-se que o empoderamento se constitui em um elemento, que associado à intervenção, pode conduzir ao desenvolvimento de dimensões do protagonismo social (Cappelletti e Martinelli, 2010). O empoderamento indica um processo utilizado para designar o conjunto de conhecimentos, que permitem a um sujeito individual ou coletivo, identificar metas e desenvolver estratégias para alcançá-las, promovendo ações efetivas para alcançar os objetivos ou desenvolvendo a capacidade de compreender a influência de seus atos sobre acontecimentos.

O empoderamento, a intervenção e o protagonismo social são integrantes fundamentais para a produção de um modelo de mediação da informação planejado, construído e experimentado em uma comunidade urbana, denominada Comunidade Santa Clara (CSC), localizada na cidade de João Pessoa, no estado da Paraíba, na região do Nordeste Brasileiro, às margens da Rodovia BR-230, entre os conjuntos residenciais Castelo Branco I e II, e o Rio Jaguaribe, nas proximidades da Universidade Federal da Paraíba (UFPB).

Há aproximadamente 450 domicílios com cerca de dois mil habitantes. A maioria dos moradores tem ocupações como domésticas, pedreiros, 
auxiliares de pedreiro e estudantes do ensino básico. Representados pela Associação, os moradores se empenham para melhorar suas condições de vida e suprir a carência da falta de escola, posto policial, biblioteca e circulação de transporte coletivo. Esses serviços são utilizados nos bairros da proximidade. Atualmente, as ações sociais que ocorrem dentro da Comunidade são promovidas pela Associação de Moradores, que implantou uma creche para abrigar e educar crianças promovendo alimentação, momentos de lazer e de sociabilidade.

Para a execução deste empreendimento de pesquisa, foi primordial apoiá-lo nos fundamentos teórico-conceituais da mediação da informação como prática social, que têm como base os pressupostos teórico-metodológicos da Ciência da Informação (CI), que, nesta investigação, foi alicerçada em uma perspectiva do paradigma social de Hjørland e Albrechtsen (com o domain-analytic paradigm e o domínio do conhecimento como comunidades do pensamento ou do discurso).

Esses alicerces em torno da pesquisa, demonstraram o quanto a questão social permeia todo trabalho teórico-metodológico em todas as etapas dentro do campo estudado, e levaram a compreensão de que a CI deveria ser vista como uma ciência social, em vez de uma ciência cognitiva (Hjørland e Albrechtsen, 1995). Além disso, refletiu-se a respeito do paradigma da apropriação da informação social na CI, onde os sujeitos são protagonistas de suas próprias histórias, e procuram se apropriar para produzir conhecimento, para benefício próprio e do seu grupo.

A apropriação da informação ocorre no processo de mediação, se constituindo em uma ação de produção e não puramente de consumo, pressupondo uma alteração, uma transformação, uma modificação do conhecimento, onde apenas o usuário pode determinar a concretização efetiva da informação (Almeida Júnior, 2007).

Além do suporte teórico mencionado, o modelo de mediação da informação é permeado pelo desenvolvimento de competências em informação, as quais foram incentivadas durante a aplicação de uma capacitação escolhida pelos próprios moradores da CSC nomeada de 'preparatório para entrevista de trabalho', que teve como objetivo estimular o desenvolvimento da consciência nos participantes da importância de se empoderar das informações necessitadas e transformá-las em ação.

Nessa perspectiva, a competência é descrita como sendo um composto de duas dimensões distintas: a primeira, um domínio de saberes e habilidades de diversas naturezas que permite a intervenção prática na realidade, no caso da segunda e mais almejada por essa pesquisa estabelece, uma visão crítica do alcance das ações, que têm em seu cerne a informação, que potencializa o 
compromisso com as necessidades mais concretas que emergem e caracterizam o atual contexto social (Feres e Belluzo, 2009). Por esta razão, denominou-se a capacitação como uma ação de informação.

Para se alcançar essas duas dimensões, como explicam os autores, foi necessário a promoção e acompanhamento de ações, a exemplo de encontros/ diálogos e da capacitação, a fim de possibilitar a apropriação de informações, bem como a reflexão de que esses moradores podem por si só mudar suas realidades, mesmo que recebam constantemente mensagens da sociedade de cunho esmagador e excludente (Farias e Freire, 2011). Entende-se que, nesse contexto, houve um processo de humanização, de conscientização do poder de transformação que há dentro de cada um.

Essas ações visam interferir no processo de exclusão social, e é justamente isso que a mediação da informação promove (Almeida Júnior, 2008), a contraposição à ideia de isolamento, passividade, ou seja, todas as transformações sociais, de uma ou outra forma, influem e exigem posturas e mudanças tanto do espaço informacional, quanto dos que nele atuam e dos serviços implantados e oferecidos.

A mediação permite (Gomes, 2010) a produção, a circulação e a apropriação da informação, o que pressupõe a existência de dispositivos. Percebe-se que a mediação da informação representa uma oportunidade de atuar junto a comunidades urbanas, para ampliar as possibilidades de ação dos sujeitos dessas comunidades no mundo, de modo a serem reconhecidos e se reconhecerem, como uma forma de motivar cada morador a lutar por melhorias para si e para a coletividade, construindo um mundo melhor no presente e para a posteridade.

Nesse sentido, a mediação da informação é compreendida como toda ação de interferência - realizada pelo profissional da informação -, direta ou indireta; singular ou plural; individual ou coletiva; que propicia a apropriação de informação que satisfaça, plena ou parcialmente, uma necessidade informacional (Almeida Júnior, 2008).

É justamente essa ação de interferência da população (usuários da informação mediada) para o desenvolvimento do protagonismo social, que promoveu-se na CSC por meio das técnicas, instrumentos, suportes, recursos, agentes e processos da mediação da informação e que deixam de ser simples artifícios de transferência de conteúdos informacionais, para se constituírem em verdadeiros dispositivos produtores de sentidos (Perrotti e Pieruccini, 2007).

A contextualização dessa pesquisa com ações, como práticas sociais e mediacionais, desenvolvidas na práxis junto com os moradores, conduz a reflexão de que a CI está imersa em um paradigma social. Esse pensamento 
pode ser confirmado pela observação de que ao desamarrar a informação de paradigmas físicos e cognitivistas, agrega-se a ela uma potência de transformação social (Gracioso, 2008).

Para que essa potência se transforme em realidade, é preciso dispor de mecanismos e metodologias eficientes, capazes de alargar a socialização da informação criando condições para que as informações sejam adequadamente distribuídas, de forma a produzir conhecimento e alcançar sua finalidade, que é promover o desenvolvimento (Varela, 2007).

Não se pode pensar na perspectiva de que os sujeitos são seus próprios mediadores, mas reflete-se sobre um trabalho em conjunto no campo de pesquisa, uma construção coletiva, de procurar ouvir/sentir o que os moradores anseiam, visualizando a Comunidade como um lugar repleto de pessoas que exprimem de diversas formas os seus desejos.

Quando os moradores se apropriam da informação inicia-se outra etapa, a discussão do valor da informação, da autorreflexão do que significa ter acesso e usar a informação para benefício próprio, isso pode ser caracterizado como sendo o empoderamento. A próxima etapa seria alcançar estágios do protagonismo social, o qual tem relação conceitual com o paradigma social da CI, ao deslocar seus atores para o papel principal, por revelar uma dimensão pessoal e ao mesmo tempo plural de convivência com o outro. Os protagonistas são simultaneamente sujeitos e objetos dos processos em que estão inseridos, produtores e criadores de significados, sentidos e práticas sociais (Perrotti e Pieruccini, 2007).

\section{Percurso metodológico}

Nesta pesquisa, todo percurso metodológico foi conduzido pelos pressupostos da abordagem qualitativa. Como método escolheu-se a pesquisa participante, pois sua potencialidade está no seu deslocamento proposital das universidades para o campo concreto da realidade. Este tipo de pesquisa modifica basicamente a estrutura acadêmica clássica na medida em que reduz as diferenças entre objeto e sujeito de estudo (Fals Borda, 1983).

A investigação ocorreu com auxílio da observação participante no acompanhamento da realidade no campo de pesquisa, fazendo uso do diário de campo. Ao coletar os dados, registrá-los coletivamente, discuti-los e contextualizá-los, constrói-se saberes visando seu compartilhamento, num processo único, dialético, transformador dos participantes e das condições existenciais: um processo que deve produzir transformações de sentido, ressignificações ao que fazemos ou pensamos (Franco, 2005). 
A observação participante foi empregada, principalmente, no momento da realização da capacitação, onde utilizou-se o diário de campo para as anotações em relação ao que foi sendo observado nos moradores, assim como dispôs-se de formulários de prospecção e roteiro de entrevista. Esses instrumentos de pesquisa foram utilizados antes, durante e após a capacitação, objetivando analisar quais competências foram desenvolvidas nos moradores da comunidade e como se encontrava o estado cognitivo desses sujeitos, suas expectativas em relação ao aprendizado antes de participarem da capacitação.

Objetivou-se com esta ação, que os moradores se tornassem disseminadores das competências em informação adquiridas, as quais foram direcionadas para o desenvolvimento de habilidades sociais, cognitivas e tecnológicas. Por esta razão, a capacitação foi aplicada, sobretudo, para as pessoas consideradas as mais ativas da comunidade. O grupo era composto por mulheres com idade entre 14 e 61 anos, o que demonstra mais uma vez a liderança feminina no contexto das comunidades. Algumas delas criam os filhos sozinhas e trabalham como diaristas para manter a casa, mas estão à procura de oportunidades melhores. Ainda participaram estudantes que nunca trabalharam e procuram o primeiro emprego, por isso buscam se preparar para o momento da primeira entrevista.

Enfatiza-se ainda que, antes de ser aplicada a capacitação, analisou-se o perfil dos interessados, por meio de entrevistas, com o objetivo de direcionar o conteúdo e a metodologia, tomando como base o conhecimento prévio dos participantes. Tendo ainda a preocupação com os aspectos cognitivos e sociais dos sujeitos, no intuito de possibilitar para eles o desenvolvimento de competências para acessar e usar criticamente a informação.

Também fez-se uso do grupo focal após a capacitação, uma técnica de pesquisa qualitativa, que se caracteriza como uma prática social, e pode estimular voz da Comunidade. O grupo focal foi constituído pelos moradores que participaram da capacitação, e foi mediado pela instrutora da capacitação e pela pesquisadora, ambas se prepararam para este momento, planejando as questões de organização, a produção de anotações das expressões e gestos diante de cada questionamento dos participantes.

Os dados coletados antes, durante e após a capacitação foram tratados a partir da técnica de análise de conteúdo (Bardin, 2009) com o estabelecimento de categorias. Ao analisar esse material, descobriu-se novas interpretações, que não estavam aparentes no momento da coleta, uma ocasião para fazer com que as falas dialogassem entre si e com os personagens envolvidos neste processo de desnudamento dos conhecimentos por eles disseminados. 
Esses dados e a experiência no campo de pesquisa permitiram a compreensão de que o processo de reflexão para o desenvolvimento de um modelo teórico é intenso. No caso desta pesquisa o modelo foi sendo construído, concomitantemente, ao aprofundamento das conceituações teóricas que alicerçam a pesquisa, bem como a efetivação das ações dentro da Comunidade Santa Clara.

\section{CONSTRUÇÃO DO MODELO DE MEDIAÇÃO DA INFORMAÇÃO}

Para se chegar à produção do modelo de mediação da informação, alguns fundamentos teóricos foram experienciados ao longo da pesquisa empírica, a cada contato e a cada ação realizada para e com a Comunidade Santa Clara. Estes testes foram sempre guiados pela mediação da informação e pelo paradigma social da CI, tendo no seu cerne, estudos direcionados para o desenvolvimento de ações, projetos e estratégias realizadas com o sujeito e não para o sujeito, considerando os interesses, as tensões, a realidade social, histórica e econômica em que cada indivíduo se encontra (Hjørland e Albrechtsen, 1995).

A teoria de Vygotsky proporcionou a compreensão de que é por meio do diálogo, da mediação e das construções socialmente elaboradas do conhecimento que é possível desenvolver uma pesquisa orientada no paradigma social da CI. Um paradigma que procura preencher as lacunas deixadas pelo paradigma cognitivo, e inserir o indivíduo no centro dos processos informacionais, em uma tentativa de possibilitar o protagonismo social, prezando pela ética do viver do outro, pela partilha da visão do outro; e tratando a informação como uma força propulsora de mudanças de estágios cognitivos.

Ressalta-se que há a consciência, de que o paradigma social é considerado como um paradigma emergente, ou seja, ele está em processo de consolidação de suas concepções teóricas e práticas, caminhando na:

constituição de fundamentos de domínios de uma comunidade discursiva e na hermenêutica da informação. Mas acima de tudo, é pertinente considerar que o paradigma social dá margem para a criação de novas percepções, interpretações e contribuições ad infinitum, visando amadurecer os estudos teóricos, epistemológicos e empíricos da CI. (Silva e Farias, 2013: 52)

Considera-se pertinente, aportar esta pesquisa, principalmente, em Hjørland e Albrechtsen para tratar do paradigma social da CI, já que os autores vêm desenvolvendo estudos nessa área desde a década de 90, propiciando a 
fertilização de um ambiente propicio a efetiva aplicabilidade desse paradigma denominado por eles como paradigma analítico do domínio 'domain-analytic paradigm', o qual estabelece que: a melhor forma para compreender a informação em CI é estudar o domínio do conhecimento como comunidades do pensamento ou do discurso, que são partes da divisão de trabalho na sociedade (Hjørland e Albrechtsen, 1995). De acordo com os autores, o domain-analytic paradigm' é um paradigma social e concebe a CI como:

uma das ciências sociais; com uma abordagem funcionalista, procura entender a função implícita e explícita da informação e comunicação, para delinear os mecanismos subjacentes ao comportamento da informação dessa compreensão; e ainda como abordagem realístico-filosófica tentando encontrar as bases para a CI em fatores que são externos para as percepções individualistas-subjetivas dos usuários em oposição, por exemplo, aos paradigmas cognitivo e behaviorista (Hjørland e Albrechtsen, 1995: 400)

A definição acima apresenta o paradigma social da CI como conjunto de estudos voltados para atividades a serem desenvolvidas com os sujeitos, e não apenas para eles, levando em consideração a realidade social, econômica, histórica e política de cada campo de pesquisa, bem como, as condições sociais de produção do habitus e capital de cada sujeito, além de seus conflitos, subjetividades, relações de força e poder, interesses, contradições e tensões que alimentam, historicamente, e progressivamente, o campo de conhecimento (Nascimento e Marteleto, 2004).

O paradigma social da CI não concebe a informação o status de "coisa" ou a restringe as formações cognitivas individuais, pelo contrário trata de inserir o sujeito como protagonista no cerne dos processos informacionais: a informação é localizada, portanto, em seus matizes históricos, econômicos, culturais, tecnológicos, sociais e políticos (Martins, 2013).

As teorias em torno do paradigma social promovem a compreensão de que, as ações de informação e as conexões necessárias entre o mediador e os mediados, pesquisador e protagonistas, só podem efetivamente ocorrer por meio do diálogo, da mediação e das construções socialmente elaboradas do conhecimento, ou seja, é preciso pensar na alteridade e se ver no outro. Por isso, em uma pesquisa com este direcionamento, visualiza-se como necessário a presença de uma prática mediacional na perspectiva de favorecer o diálogo e as conexões necessárias entre o mediador e os sujeitos da pesquisa.

Os fundamentos teóricos consagrados no campo da Ciência da Informação, que serviram de inspiração durante o processo de planejamento, construção e experimentação do modelo de mediação da informação da pesquisa, foram: 
Modelo comunicação todos-todos (Mendonça, 2007) - a teoria deste modelo auxiliou na compreensão do processo comunicativo, bem como na identificação de um processo de construção colaborativa do conhecimento, capaz de viabilizar ações de informação que tenham, por exemplo, o objetivo de promover a aprendizagem. Isso significa dizer que há um "colóquio" entre a informação, comunicação e educação, o que proporciona a produção e disseminação de conhecimento e de saberes.

Neste modelo comunicação todos-todos percebe-se a ocorrência da ampliação de diálogos participativos, em um processo vivo e dinâmico, no qual o sujeito pode se manter e até mesmo expandir sua identidade cultural e os valores a ela agregada, o que possibilita uma melhor compreensão da realidade social que o cerca e as relações/laços que constituem seu mundo.

Essas reflexões levaram a planejar a capacitação, a partir da elaboração conteúdos interativos, inclusivos, com forte senso de ação comunicativa. $\mathrm{Ou}$ seja, a intenção foi realmente produzir um conhecimento edificado a partir da história de vida dos moradores da CSC, mediado e redesenhado para ser aplicado naquela realidade, a qual pertence os receptores e produtores, onde ocorrem as trocas de saber de forma colaborativa e livre, e as informações não são apenas consumidas, mas também disseminadas, conforme relato dos próprios moradores da Comunidade, que ao participaram da capacitação esboçaram esse desejo de propagar o conhecimento adquirido.

Modelo de desenvolvimento humano e Modelo de desenvolvimento de competências intelectuais de informação (Sirvent, 1984) - o primeiro modelo de Sirvent portou o entendimento da importância do diagnóstico da situação dos sujeitos da pesquisa, no que concerne verificar se há indícios do protagonismo social, que segundo Sirvent tem como foco condutas participativas, pensamento reflexivo, criativo-recreativo, valorização de si e do grupo ao qual pertence. Tendo essas prerrogativas como parâmetro deve-se observar a realidade dos sujeitos, o que fazem, o que necessitam, o que desejam, o que pensam sobre si mesmos e sobre o contexto em que vivem.

Alguns destes elementos foram observados durante a capacitação, principalmente no decorrer da dinâmica de grupo. Não tem-se nesta pesquisa a pretensão de dizer que o protagonismo social foi plenamente alcançado, ele requer diversos estágios, mas é possível mostrar, por meio dos dados analisados, que há indícios de valorização pessoal dos participantes da capacitação, bem como o início do pensamento reflexivo quanto à preparação para o futuro, para o mundo do trabalho, e sobre fatos e situações problemáticas do cotidiano.

O segundo modelo de Sirvent é composto de três elementos (o fato, a análise e a ação) e trata do desenvolvimento de competências intelectuais de 
informação. Este modelo sintetiza justamente a metodologia de ação empregada dentro Comunidade Santa Clara, onde foi preciso fazer o diagnóstico, como explicado anteriormente, que seria o fato: uma visualização da realidade, das necessidades informacionais, dos possíveis recursos a serem utilizados. A segunda fase a análise, se caracteriza como o momento de reflexão sobre a realidade identificada, e também das possíveis ações a serem implantadas para suprir as necessidades. A última etapa é composta pela efetivação das ações empreendidas.

$\mathrm{O}$ pesquisador seguiu esse percurso, e deseja que os sujeitos da pesquisa possam executá-lo em suas vidas, como por exemplo, saber da necessidade de obter um trabalho (fato), pensar nas formas de obtê-lo, se preparando para isso (análise) e se candidatar as vagas, por exemplo, em agências de trabalho (ação).

Modelo comportamento informacional (Wilson, 1996) - os elementos deste modelo foram utilizados para identificar as necessidades de informação dos participantes da capacitação, bem como no comportamento durante a busca e a disseminação de informação, principalmente, porque Wilson incluiu em sua última versão do modelo a etapa, a pessoa-em-contexto, e a decisão de buscar informações. Ou seja, ao analisar os moradores da Comunidade em sua realidade, verificou-se a partir deste contexto, o comportamento informacional, a busca pela informação, as possíveis barreiras, como demonstrado na interpretação dos dados coletados, quando uma moradora procura superar a barreira tecnológica - uma variável pessoal - e utiliza as habilidades da filha para obter as informações necessárias para suprir sua expectativa.

Um modelo seria uma representação de um recorte da realidade, com uma função utilitária, e por meio do seu modo de expressão, sua estrutura e suas igualdades e desigualdades em relação ao seu original, tenta comunicar algo sobre o real (Sayão, 2001).

Conforme este modelo de Wilson, pode-se envolver outras pessoas na busca e também na troca de informações. Quando a informação é percebida como útil, na versão do modelo de 1981, Wilson utiliza o termo exchange (troca) para chamar a atenção para o elemento de reciprocidade, reconhecido por sociólogos e psicólogos sociais como um aspecto fundamental da interação humana. Sabe-se que, durante todo o processo de construção do modelo de mediação da informação, diversas barreiras poderiam surgir, até mesmo neste momento de representação gráfica do modelo, a qual concebe o olhar e a interpretação do pesquisador sobre o que ocorreu no campo de pesquisa.

Modelo mediação potencializadora do desenvolvimento integral e Modelo mediar com visão inclusiva (Belmonte, 2007) - esses dois modelos de Belmonte se complementam por trazer para a mediação a função humanizadora, 
com potencial para impulsionar o desenvolvimento cognitivo e intelectual do ser humano. Como explica o autor, a mediação é uma qualidade essencial à interação, é uma fonte de transmissão cultural, significativa, afetiva, é orientação ao pensamento casual, estabelecendo relações, avançando os efeitos de um ato.

Os elementos que Belmonte utilizou no modelo de mediação potencializadora do desenvolvimento integral se assemelham as competências do mediador para atuar no campo de pesquisa e detectadas no mediado após as ações empreendidas na Comunidade, quais sejam: acompanhamento e proximidade; encontro ou a relação profundamente humana; despertar a autoestima; ajudar a clarificar e discernir as experiências; ensinar a ver, a contemplar; dotar o mediado de estratégias de aprendizagem para a formação de habilidades cognitivas.

Verifica-se que houve um processo de modificação no mediador e nos mediados, o que significa criar novas disposições no ser humano, ampliar o mundo das relações, superar a percepção episódica da realidade, desenvolver novas perspectivas e novos significados (Belmonte, 2007). Ao analisar o segundo modelo de Belmonte, mediar com visão inclusiva, visualiza-se também as competências do mediador e dos mediados, identificadas pela pesquisa. A mediação potencializadora é a mediação que inclui, que procura respeitar e incentivar/convocar a identidade social que cada ser deveria ter de si próprio, da realidade que o cerca, reconhecendo o sistema de crenças que circunda o indivíduo.

Modelo básico de aprendizagem e memória subjacente nas teorias modernas de "processamento de informação" (Gagné, 1980) - este modelo muniu esta investigação, principalmente, de elementos para a trajetória de montagem da capacitação, e desempenha no modelo de mediação da informação desta pesquisa uma função de orientador para a compreensão do processamento de informação, do que possivelmente ocorre internamente no indivíduo.

O modelo de Gagné proporcionou a compreensão de que, para verificar se existiu a aprendizagem é preciso observar se houve uma mudança comportamental relativamente persistente, averiguando, por exemplo, se durante a dinâmica de grupo (simulação de entrevista de trabalho) os participantes se comportaram, de acordo com os ensinamentos disseminados durante a exposição teórica da capacitação, se eles absorveram as informações propagadas e conseguiram formar um quadro mental, demonstrando dessa forma um evento de aprendizagem.

Os elementos do modelo de Gagné evidenciam, ao final, que o ato de aprendizagem é resultado da interação entre o indivíduo e seu ambiente, e ainda que o processo que aconteceu na mente do sujeito só pode ser inferido 
a partir de observações realizadas externamente, através das ações que o sujeito promove.

Após discorrer a respeito dos modelos que guiaram a pesquisa de campo, apresenta-se o modelo de mediação da informação (Figura 1), cujo objetivo geral se concentra em analisar o processo de produção e experimentação de um modelo de mediação da informação, com vistas a oferecer subsídios teórico-metodológicos para promoção do protagonismo social nos moradores da Comunidade Santa Clara. Os elementos que compõem o modelo são: moradores da CSC/líder comunitária; capacitação/aprendizagem; desenvolvimento de competências/mediação; empoderamento/apropriação da informação; e protagonismo social/tornar-se sujeito na plenitude; mediação, informação, conhecimento, inteligência e comunicação.

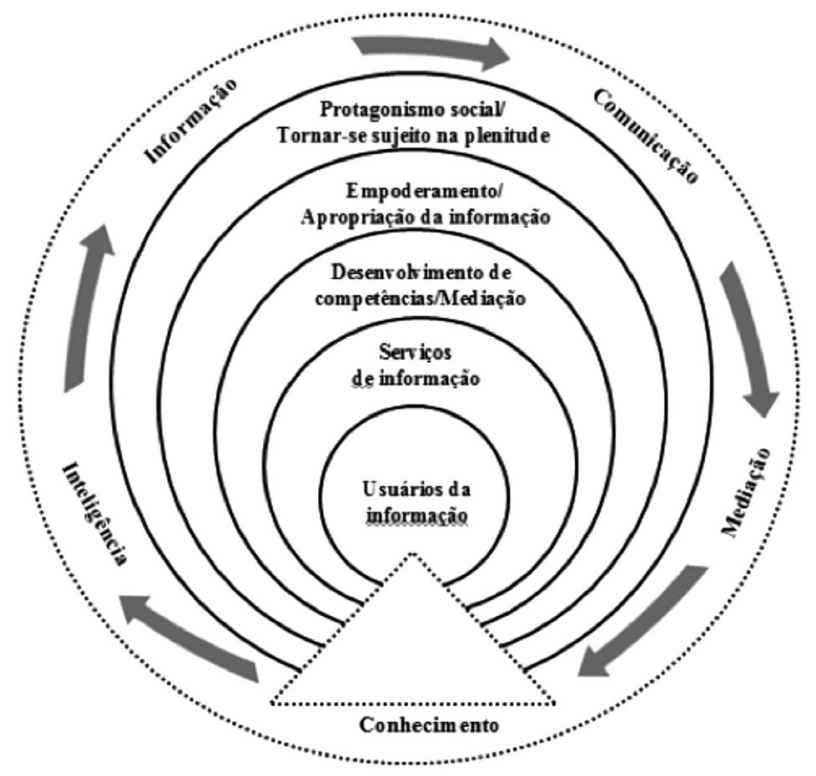

Figura 1. Modelo de mediação da informação. (Dados da pesquisa, 2014)

Os moradores da CSC são os sujeitos da pesquisa, são os que participaram dos encontros e da capacitação, e para quem direcionou-se todos os esforços para atingir os objetivos desta investigação, afinal empreendeu-se ações pautadas pelo paradigma social da Ciência da Informação, com foco nos sujeitos, no desejo de facilitar a produção de conhecimentos e incentivar o processo de conscientização destes moradores, para se mobilizarem, se empoderarem das informações e caminharem em direção ao protagonismo social. 
A líder comunitária desempenha um relevante papel, pois é ela quem criou a rede de amigos, que socorre os casos mais urgentes na Comunidade, tenta conscientizar os moradores da importância de estudar, de procurar trabalho e ter uma vida mais digna. Por isso, destaca-se que todo trabalho a ser realizado em uma comunidade urbana, deve ter o apoio do líder comunitário, esta deveria ser a primeira pessoa com quem o pesquisador precisaria ter contato. No caso específico da Santa Clara, a líder é uma fonte de informação utilizada pela maioria dos moradores, todos a conhecem e a respeitam, tiram suas dúvidas e pedem auxílio em várias questões.

A capacitação e aprendizagem estão em um mesmo espaço no modelo por se complementarem, e porque a capacitação foi uma ação de informação de cunho educativo, que objetivou promover a aprendizagem, valorizando os hábitos, a cultura local, respeitando a forma de cada morador ser e agir, incentivando a autonomia, valorizando os saberes individuais e do grupo, suas habilidades e competências.

A capacitação foi permeada pela mediação de caráter pedagógico - esse tipo de mediação advém quando o profissional da informação assume a posição de formador, e atua para que as interações educativas aconteçam, para que a relação aprendiz-saberes seja efetivada levando à aprendizagem (Davallon, 2003).

A montagem da capacitação foi conduzida com base numa construção compartilhada e centrada no social, com a localização de algumas brechas cognitivas e necessidades de informação dos moradores, as quais procurou-se preencher como a confecção de um conteúdo com foco nas teorias de Piaget, que pregam o respeito à metodologia de aprendizagem, à valorização do ser humano e de suas faculdades intelectuais, do entendimento que o conhecimento se desenvolve por meio de interações sociais em uma construção progressiva. Ao final, espera-se que os participantes tenham compreendido a necessidade do saber-fazer, da construção de estratégias e ações para tentar superar as barreiras que a vida lhes impõe.

O próximo estágio do modelo está contemplado pelos elementos desenvolvimento de competências e mediação. Para desenvolver competências é preciso haver um movimento constante de aprendizagem, levando em consideração as necessidades cognitivas e sociais dos sujeitos, respeitando sua forma de agir e incentivando-os a prosseguir, a desejar as transformações benéficas, apesar de todas as dificuldades.

Foi a partir desta reflexão que preparou-se a capacitação, visando proporcionar aos participantes a compreensão da necessidade de procurar desenvolver um conjunto de habilidades, de integrar múltiplos saberes, o que promoverá a preparação deles para o mercado de trabalho, para o que buscam as 
empresas. A consequência desta preparação pode ser verificada ao observar as falas dos moradores, que demonstram ter compreendido a premência de desenvolver competências para melhorarem de vida, para se sentirem cidadãos ao participarem dos processos sociais.

A mediação surge novamente neste estágio do modelo, pois ela também está em todas as fases, e o estímulo ao desenvolvimento de competências nos indivíduos só pode ocorrer por meio da mediação da informação, uma mediação social, pedagógica, que se configura como uma ação de interferência, essencial para o estabelecimento do diálogo, para a disseminação da informação. O conhecimento é uma produção cultural, diretamente relacionada à linguagem, e a mediação é a ação que se interpõe entre sujeito e objeto de aprendizagem (Vygotsky, 1991).

É justamente através da mediação que se pode chegar à apropriação da informação e ao empoderamento. No caso desta pesquisa, a capacitação se caracteriza como nosso principal instrumento em direção ao empoderamento, ou melhor, a um dos graus do empoderamento, que é a preparação do homem para o trabalho. Como já explicou-se, há graus de empoderamento, nunca se é totalmente empoderado, este não é um conceito que pode ser visto de forma generalizada (Horochovski e Meirelles, 2007).

Foi por meio da mediação e do diálogo que percebeu-se indícios de que os participantes da capacitação, atingiram o grau do empoderamento ligado à apropriação das informações mediadas, à conscientização da importância de obter informações necessárias à busca por trabalho. Durante a dinâmica de grupo constatou-se o empoderamento, quando os participantes passaram por uma entrevista de trabalho fictícia e externalizaram por gestos e palavras, quais as informações cada um deles havia internalizado, transformando-as em conhecimento.

É justamente no último estágio do modelo que se encontra o desejo latente desta pesquisa, o protagonismo social, o tornar-se sujeito na plenitude. A informação mediada tem o poder de levar o sujeito ao protagonismo social. Este é um processo lento, que deve ser bem planejado, por exemplo, por profissionais da informação, que podem mergulhar na realidade dos sujeitos de uma pesquisa, buscando nas suas raízes os subsídios para promover o conhecimento.

É um processo que requer uma alta dosagem de alteridade, de autoconhecimento, de se ver, de se reconhecer no outro, e procurar compreender que o outro é o mediador indispensável entre mim e mim mesmo (Sartre, 1943). $\mathrm{O}$ autoconhecimento seria uma forma primeira de formação de uma competência essencial a de sujeito cognoscente. A alteridade envolve mediação quando do reconhecimento das diferenças, incide sobre um significado coletivo de informação. 
Essas são características/competências essenciais a um mediador, sem ela não se pode pensar em planejar uma ação de intervenção para a promoção do protagonismo social, o qual visa deslocar seus atores para o papel principal, por revelar uma dimensão pessoal e ao mesmo tempo plural de convivência com o outro, com a comunidade a qual pertence, promovendo ações de diversos níveis, inclusive informacionais, e potencializado uma dinâmica social e cultural no seu contexto, e na sociedade.

Atingir o protagonismo social é se tornar um sujeito na plenitude, é participar ativamente de processos decisórios, é consumir e produzir, ser mediador e mediado de práticas sociais. Ser protagonista é ser capaz de expressar seus desejos, suas ideias, valorizando o seu saber, mesmo que seja proveniente do senso comum, participando de forma ativa do espaço público. Participar das práticas sociais desenvolvedoras de possibilidades emancipatórias, que contribuem para a construção de uma nova cultura e de uma visão crítica do mundo, mas para isso é preciso lutar contra pensamentos arraigados e deslocados historicamente pela tutela dos que manipulam o conhecimento e o acesso a ele (Luiz, 2009).

Sabe-se que antes de ser protagonista é preciso ter as necessidades básicas supridas, como alimentação, saúde, segurança e educação. Foi nesta última necessidade que interviu-se, no sentido de possibilitar o acesso ao trabalho, a uma remuneração para suprir outras necessidades, o que ajuda também na constituição da autoestima dos sujeitos, ao se sentirem valorizados, a produzirem bens ou serviços e serem remunerados por isso.

Dessa forma, o acesso ao trabalho se configura como sendo um das dimensões para se chegar ao protagonismo social. Atuou-se para preparar os moradores da Comunidade Santa Clara, que participaram da capacitação, para chegarem à dimensão acesso ao trabalho. Esta foi a principal contribuição desta pesquisa, sem pretensão de afirmar que promoveu-se de forma integral o protagonismo social nos moradores da CSC, mas sim que atingiu-se uma das suas dimensões/estágios.

Os elementos em volta dos estágios do modelo: informação, comunicação, mediação, conhecimento e inteligência, estiveram presentes em todas as fases do planejamento, produção e experimentação do modelo, bem como na descrição de cada estágio apresentado. A informação é um potencial insumo para produzir transformações se for adequadamente comunicada, ou seja, se houver nesta comunicação, a mediação, a troca, o diálogo, o respeito aos sujeitos que são os receptores e virão a se tornar agentes promotores, desde que a informação tenha se transformado em conbecimento, isto é, se houve realmente internalização, a ativação da rede neural, do instrumento mental, da inteligência do usuário/mediado/receptor. 
Ao final, todos os elementos contribuem para o crescimento do sujeito, para a disseminação e produção do conhecimento. Acrescenta-se ainda que, o triângulo dentro dos círculos significa um ponto de interseção de todos os estágios do modelo, que tem no centro os sujeitos para quem todas as ações foram empreendidas.

Esse modelo comporta em seu cerne, a compreensão de que a mediação da informação, no contexto de uma comunidade, deve ocorrer em uma perspectiva consciente, a partir de uma abordagem ético-informacional e não proselitista, ou seja, não arbitrária, manipuladora, unilateral ou forçosa. $\mathrm{O}$ proselitismo pode ser utilizado justamente como princípio de oposição ao trabalho/pesquisa para e com os sujeitos, ele torna o outro um objeto estanque, indo de encontro às concepções da mediação. Por isso, o mediador precisa estar preparado e fundamentado nas bases teóricas da mediação da informação, para promoção de ações com vistas ao desenvolvimento do protagonismo social.

\section{CONSIDERAÇÕES FINAIS}

As reflexões suscitadas por esta investigação, provocam a compreensão de que um modelo de mediação da informação pode possibilitar o protagonismo social, por meio do empoderamento, em moradores de uma comunidade urbana, se desenvolvido a partir dos pressupostos teóricos do paradigma social da CI, funcionando como um suporte para o desenvolvimento de competências por meio da aprendizagem mediada.

Observou-se na Comunidade Santa Clara como as interações sociais se constituem em um espaço social, onde as ações de informação ocorreram em um movimento de reconstrução desse espaço físico, tornando-o um lugar para além das heterotopias, um lugar repleto de representações e de manifestações culturais, sociais e históricas. Pode-se inferir que as ações realizadas na CSC para e com os moradores produzem conhecimentos, principalmente, a interação dos sujeitos com o meio onde vivem, a partir da carga cultural e histórica que eles trazem, o que está intrinsicamente ligado à prática social.

Destaca-se também que os laços sociais e a identidade de grupos precisam ser repensados, no sentido de considerar que só a partir do respeito pelo diferente, que se pode compreender o sujeito como único, mas que precisa do outro e de tudo o que o rodeia, e da união para sair do estado de degradação. A única dimensão possível é aquela da experimentação contínua, essa opção, no entanto, requer uma leitura permanente das condições do contexto, um acompanhamento constante de processos, uma presença assídua nos 
pontos de fragilidade, empreendendo ações voltadas para a escolarização e para a formação.

Nesta perspectiva, esforços devem ser empreendidos para identificar barreiras na mediação e vencê-las pelos canais de comunicação, das fontes, das possibilidades, da comunicação oral, identificando qual a linguagem usar nesse contexto social da comunidade, e quais os meios comunicacionais utilizados para melhorar as barreiras. Transcender o conceito de mediador para ressignificar e transformar o mundo, pode provocar o fortalecimento de constructos teóricos da mediação da informação.

Durante esta pesquisa, tal transcendência ocorreu quando o mediador, dentro do campo de pesquisa, no processo de codificação e decodificação das informações repassadas pelos sujeitos da pesquisa, interpretou-as a partir daquela realidade social, visualizando as brechas a serem preenchidas. Essa seria a plenitude de trabalho de um mediador, de ir além da superfície das demandas, do que está sendo solicitado, procurando entender o lugar do profissional da informação, localizando as lacunas e preenchendo-as ao proporcionar mais informações para os moradores, não só na função imediatista, mas mostrando a complexidade e o desejo de quem medeia, que é provocar no outro uma função.

A introdução dos princípios do protagonismo social fortalece as ações de informação e deve estar atrelado à oportunidade de possibilitar formas concretas, reais e legítimas de apropriação da informação, de empoderamento cultural e social. Obviamente não se tem controle ou poder sobre a informação, seja ela implícita ou explícita, mas pode-se desenvolver uma autoconsciência da relevância da informação para a dinamização do protagonismo, baseado na premissa de que só a partir de ações dialógicas e conjuntas, e do entendimento de que não há autossuficiência em um trabalho dessa dimensão, que os sujeitos podem se tornar protagonistas.

Conclui-se que na Comunidade Santa Clara as interações sociais estão constituindo, de forma lenta e progressiva, um espaço social, onde se experimenta um movimento de reconstrução do espaço físico, tornando-se um lugar além da heterotopia, um lugar cheio de representações e eventos culturais, sociais e históricos. O esforço da líder comunitária pode ser considerado como uma gota d'água no oceano de pessoas em situação de fragilidade, que precisam de direcionamentos e incentivos. Instituições, organizações, universidades têm a possibilidade de atuar, neste contexto, com projetos de extensão e de pesquisas, no sentido de estudar essas realidades e descobrir possíveis caminhos para autonomia dos sujeitos necessitados, utilizando a informação como instrumento. 


\section{REFERÊNCIAS}

Almeida Júnior, O. F. de. 2007. "Leitura, mediação e apropriação da informação”, em A leitura como prática pedagógica na formação do profissional da informação, J. P. Santos (Org.), 33-45. Rio de Janeiro: Fundação Biblioteca Nacional.

Almeida Júnior, O. F. de. 2008. "Mediação da informação: ampliando o conceito de disseminação", em Gestão da Informação e do Conbecimento, M. Valentim (Org.), 41-54. São Paulo: Editora Polis.

Bardin, L. 2009. Análise de conteúdo. Lisboa: Edições 70, LDA.

Belmonte, L. T. 2007. El profesor mediador del aprendizaje. Chile: Arrayán Editores.

Caltabiano, C. 2006. Gli anticorpi della società civile: nono rapporto sull'associazionismo sociale. Roma. http://www.ideeinrete.coop/aggiunte/rapporto_associazionismo.pdf

Cappelletti, P. e M. Martinelli. 2010. Animare la città. Percorsi di community building. Trento, Itália: Erickson.

Davallon, J. 2003. "La médiation ou la communication en procès?". Médiation EInformation (MEI) 19: 39-59. Paris: L'Harmattan.

Fals Borda, O. 1983. "Aspectos teóricos da pesquisa participante: considerações sobre o significado e o papel da ciência na participação popular”, em Pesquisa participante, 3. ed., C. R. Brandão (Org.), 42-62. São Paulo: Editora Brasiliense.

Farias, M. G. G. e I. M. Freire. 2011. "Ação de mediação para inclusão social de comunidades”. Informação E Informação 16 (3) (jan./jun.): 76-95. Londrina.

Farias, M. G. G., A. V. Varela e I. M. Freire, I. M. 2013. "Information Mediation for Social Inclusion in a Poor Urban Community in Brazil”. De Gruyter: Libri 63 (3): 179-189.

Feres, G. G. e R. C. B. Belluzzo. 2009. "Competência em informação: um diferencial da qualidade em publicações científicas”. Revista Brasileira de Biblioteconomia e Documentação 5 (1/2) (jan./dez.): 70-83. Nova Série, São Paulo.

Franco, M. A. S. 2005. "Pedagogia da pesquisa-ação". Educação e Pesquisa 31 (3) (set./dez.): 483-502. São Paulo.

Gagné, R. M. 1980. Princípios Essenciais da Aprendizagem para o Ensino. Porto Alegre: Ed. Globo.

Gomes, H. F. 2010. “Tendências de pesquisa sobre mediação, circulação e apropriação da informação no Brasil: estudo em periódicos e anais dos ENANCIB (2008-2009)". Pesquisa Brasileira em Ciência da Informação 3 (1) (jan./dez.): 8599. Brasília, DF.

Gracioso, L. de S. 2008. "Filosofia da linguagem e ciência da informação: jogos de linguagem e ação comunicativa no contexto das ações de informação em tecnologias virtuais". Tese. (Doutorado em Ciência da Informação) - Universidade Federal Fluminense; Instituto Brasileiro de Informação em Ciência e Tecnologia, Programa de pós-graduação em Ciência da informação. Rio de Janeiro-RJ: UFF/ IBICT/PPGCI.

Hjørland, B. e H. Albrechtsen. 1995. "Toward a new horizon in information science: domain-analysis". Journal of the American Society of Information Science 46 (6): 400-425.

Horochovski, R. R. e G. Meirelles. 2007. "Problematizando o conceito de empoderamento", in Seminário Nacional Movimentos Sociais, Participação e Democracia, 
II, Núcleo de Pesquisa em Movimentos Sociais - NPMS, 2007, Florianópolis, Anais... Florianópolis: UFSC. p. 485-506.

Klein, O. J. 2009. "Para compreender o protagonismo social na construção do telejornalismo em rede”, em Congresso Brasileiro de Ciências da Comunicação, XXXII, 2009, Curitiba. Anais..., Curitiba: Intercom - Sociedade Brasileira de Estudos Interdisciplinares da Comunicação, 1-13.

Luiz, D. E. C. 2009. "Capacitação e emancipação: uma relação possível”. Revista Textos $\mathcal{E}$ Contextos 8 (1) (jan./jun.): 68-88. Porto Alegre.

Perrotti, E. e I. Pieruccini. 2007. "Infoeducação: saberes e fazeres da contemporaneidade”, em Informação e contemporaneidade: perspectivas, M. L. de Lara, A. Fujino e D. P. Noronha (Orgs.), 47-96. Recife: Néctar.

Martins, A. A. L. 2013. "Mediação informacional: uma perspectiva a partir do campo social da informação”, Encontro Nacional de Pesquisa em Ciência da Informação, 14., Florianópolis. Anais..., 1-20. Florianópolis: UFSC.

Mendonça, A. V. M. 2007. Os processos de comunicação e o modelo todos-todos: uma relação possivel com o programa saúde da família. Série Tempus. Brasília: CID/ UNB; NESP.

Nascimento, D. M. e R. M. Marteleto. 2004. "A informação construída nos meandros dos conceitos da teoria social de Pierre Bordieu”. DataGramaZero: Revista de Ciência da Informação (Porto Alegre) 5 (5) (out.): 1-11.

Sartre, J. P. 1943. L'êntre et le néant. París: Gallimard.

Sayão, L. F. 2001. "Modelos teóricos em ciência da informação: abstração e método científico”. Ciência da informação 30 (1) (jan./abr.): 82-91. Brasília, DF.

Silva, J. C. L. e Maria G. G. Farias. 2013. "Reflexões teóricas sobre a construção paradigmática da Ciência da Informação: considerações acerca do(s) paradigma(s) cognitivo(s) e social”. Biblios 51: 42-56. Lima, Peru

Sirvent, M. T. 1984. Educação comunitária: a experiência do Espírito Santo. São Paulo: Editora Brasiliense.

Varela, A. V. 2007. Informação e Construção da Cidadania, v. 1. Brasília: Thesaurus.

Vygotsky, L. S. 1991. A formação social da mente: o desenvolvimento dos processos psicológicos superiores, 4. ed. São Paulo: Martins Fontes.

Wilson, T. D. 1996. Information bebaviour, an interdisciplinary perspective. http://informationr.net/tdw/publ/infbehav/

Para citar este texto:

Guedes Farías, Maria Giovanna y Aida Varela Varela. 2017. "La mediación de la ainformación y el protagonismo social": experimentando la construcción de un odelo en una comunidad brasilenã”. Investigación Bibliotecológica: archivonomia, bibliotecología e información 73 (31): 91-110.

http://dx.doi.org/10.22201/iibi.24488321xe.2017.73.57848 